\title{
Stress Mediates the Relationship between Personality and the Affordance of Socially Distanced Online Education
}

\author{
Damian J. Rivers \\ Center for Meta-Learning, Future University Hakodate, 116-2 Kamedanakano, Hakodate, Hokkaido 041-8655, Japan \\ Correspondence should be addressed to Damian J. Rivers; rivers@fun.ac.jp
}

Received 22 November 2021; Accepted 13 January 2022; Published 4 February 2022

Academic Editor: Zheng Yan

Copyright ( 2022 Damian J. Rivers. This is an open access article distributed under the Creative Commons Attribution License, which permits unrestricted use, distribution, and reproduction in any medium, provided the original work is properly cited.

\begin{abstract}
The novel coronavirus pandemic has made life significantly more stressful for large populations of people. As one such demographic, university students worldwide have experienced a sudden shift toward the provision of socially distanced online education, often in the absence of a coherent institutional plan. The mechanisms of stress appraisal and response differ between individuals in part determined by personality. With a sample of 293 undergraduate students at a Japanese university operating under prohibitions relating to face-to-face education, this article examines the impact of personality on the affordance of socially distanced online education mediated through generalized life stress and online learning stress appraisal. A retrimmed structural model returned an acceptable goodness of fit accounting for $31.6 \%$ of the criterion variance. The model indicates that conscientiousness (positive) and neuroticism (negative) hold a significant mediated impact on the affordance of socially distanced online education through generalized life stress and online learning stress appraisal. Moreover, and in the absence of face-to-face social interaction, the model shows that extroverted students experience greater online learning stress appraisals than neurotic students. Neurotic students were, however, negatively impacted by appraisals of generalized life stress but not online learning stress. Informed by personality characteristics and stress appraisals, the outcomes are discussed in relation to educational improvements and appropriate pedagogies for the delivery of socially distanced online education.
\end{abstract}

\section{Introduction}

The novel coronavirus pandemic has exerted a profound impact on public mental health contributing to an increase in depression, anxiety, insomnia, and stress appraisal [1-5]. As a defensive physiological, psychological, and behavioral reaction, stress can be understood as the disruption arising from a perception that threat demands exceed one's adaptive mitigation capacity [6]. The transactional stress theory $[7,8]$ contends that stress as an objective variable is present neither within the individual nor the environment but rather is emergent via an abstract relationship wherein "the separate person and situation elements are joined together to form a new relational meaning" ([9]: 294). The mechanisms of stress appraisal and coping are known to differ significantly between individuals [10] and are at least partially determined by personality [11-13]. Personality "not only affects the appraisal of and coping with stress, but it is also crucial with regard to the selection and shaping of stressful situations" ([14]: 335). Certain individuals are therefore more predetermined to experience and respond to stress based on personality characteristics $[15,16]$.

Prior to the novel coronavirus pandemic, a declassified Organization for Economic Co-operation and Development (OECD) report contextualized education within an emergent volatile, uncertain, complex, and ambiguous global environment [17]. The pandemic has exacerbated these concerns and situated education as a stressful domain for various stakeholders including students. In the context of Japanese society, a recent Japan Times (2021, February 28) [18] article entitled "COVID-19 pushes 1,300 Japanese university students to drop out" documents how many students have quit university due to an inability to pay tuition fees, loneliness and isolation, and an inability to make friends through online education, factors which also had a negative impact upon motivation to study. Beyond Japan, a plethora of recent studies have 
highlighted increases in stress among students brought about by conditions surrounding the pandemic [13, 19-27]. These studies are important as mental health problems among students are associated with reduced academic performance, substance abuse, poor physical health, increased dropout rates, and avoidance-based coping strategies [28-33].

The pandemic has exposed inadequacies within many education systems around the world and drawn attention to the need for stakeholders to reassess established educational models, practices, and relationships. One of the most dramatic areas for reassessment concerns the unexpected demand for face-to-face courses to be delivered online [34], thus changing the ways in which educational communities interact, communicate, and learn. Throughout the pandemic, Japanese universities have remained operational although a lack of institutional readiness for online education has been exposed [35-37]. While a recent report from the Japanese Ministry of Education, Culture, Sports, Science, and Technology (MEXT) ([38]: 15) declares an additional $\$ 95$ million "for support in preparing an IT environment that will enable universities to set up a system and equipment for conducting distance learning classes and to provide advanced education using digital technology," conceptualizations of successful online education in Japan are often limited to rhetoric and an overemphasis on technological infrastructure. There exists a marked absence of educational discourse pertaining to institutional culture reforms, teaching pedagogies, and professional development initiatives $[39,40]$. If the new status quo is to be accepted as sufficient to support changing educational goals and learning needs, then it is important to consider the affordance of socially distanced online education as impacted by appraisals of stress surrounding the novel coronavirus pandemic.

Situated within a Japanese information systems university operating under prohibitions relating to face-to-face education, this article examines the impact of personality and stress appraisal on the affordance of socially distanced online education. As the transactional stress theory emphasizes the mediated relationship between individuals and their environment in stress appraisal and coping responses $[7,8]$, personality traits represent an appropriate focal point in the study of stress appraisal related to pandemic restrictions and the enforced provision of socially distanced online education. Moreover, various connections have been made between personality and technology use inclusive of learning management systems [41-45]. The primary hypothesis directing the current research is that stress appraisals mediate the relationship between personality and the affordance of socially distanced online education. Interdisciplinary research such as the current study is necessary if the widespread provision of online learning solutions is to be resilient to future stressors arising from within the volatile, uncertain, complex, and ambiguous global environment including those brought into focus by the novel coronavirus pandemic.

\section{Background Literature}

2.1. Online Education and Affordances. The closure of universities and prohibitions on face-to-face contact have impacted the mental health of students as evidenced in various multinational studies [46-48]. In a cross-sectional study, one-third of students experienced stress and anxiety relating to pandemic restrictions. The authors caution that it is vital for universities to establish and maintain connections with students during times of crisis to support psychological and social well-being [49]. In a study of university students in the United States, almost two-thirds of the sample reported increased stress and anxiety during the pandemic while less than half believed they were equipped to cope with the situation [5]. Similarly, in a study of students from three universities in China, over two-thirds of the population indicated moderate to high-stress levels during the pandemic [50].

Reasons for increases in stress among students include being distanced from the regular university life experience and social interaction with peers and teachers [51] and negative emotional responses such as anxiety, boredom, isolation, and frustration [52]. These negative responses have been exacerbated in courses delivered on-demand wherein direct social interaction with teachers and peers is absent or infrequent [53]. Questions have also been raised in relation to equality of access to digital technologies among students [54] in addition to the promotion of stress, anxiety, and other life disturbances through prolonged exposure to digital devices $[55,56]$. Other studies have shown that restrictions surrounding the pandemic have impacted student motivation [57] and student satisfaction [58].

The acceptance and use of educational technologies including learning management systems have been studied in relation to a plethora of factors $[59,60]$. Online ecosystems through which learning materials are delivered are informed by psychological principles of design pertaining to the speculated needs of an intended user. Such user needs can be framed as affordances or the motivational properties emergent between an object (i.e., a learning platform or technology such as Moodle) and an agent (i.e., a technology user such as a student). Gibson [61] argues that affordances resist the objective-subjective dichotomy as their realization is dependent upon an active agent being perceptually aware of contextual possibilities. Affordances have been used to structure and analyze technological design initiatives and evaluations across various domains [62, 63].

Effective affordances prompt individuals to engage in actions which satisfy needs resultant from an actual or imagined deprivation (e.g., the sudden absence of face-to-face learning opportunities). The affordance of online education concerns a complex mechanism of intertwined variables. While affordances may initially be drawn from the technological provisions of the experiences (e.g., the features of the learning management system used), there are many additional factors which shape the relationship between the system and the user. These include variability in individual teacher/student behaviors, competencies, and beliefs about learning and technology; the quality of learning materials and tasks given; the level of social interaction required, the forms of assessment used; and the self-regulatory abilities of students. 
2.2. Personality and Stress. The five-factor model of personality remains a robust taxonomy of individual differences [64-67]. The role of personality in the appraisal of stress has been shown through various studies with findings indicating that neuroticism plays a dominant role [68]. As a maladaptive personality trait, neuroticism indicates a predisposition to stress in the form of negative emotions and the negative framing of experience [69, 70]. These negative emotions further promote irrational thought patterns and a decreased ability to control self-motivation. Neurotic individuals can be expected to interpret everyday situations as threatening and thus experience high levels of day-today hassle [71]. Neuroticism is linked to irrational thought processes and a sense of helplessness when confronted with problematic situations. Neurotic individuals are believed to be less able to control impulses even when the result of acting upon an impulse returns negative results in the form of increased stressors [72]. Neuroticism is also believed to be a reliable predictor of reduced life satisfaction [73]. An Iranian study into the predictive value of personality in diagnosing stress, anxiety, and depression found that neuroticism was the only significant predictor of all three mental health problems [74]. Similarly, a Finnish study that sought to ascertain university student interest in using a stress management app reported that extraversion, agreeableness, and conscientiousness were associated with lower self-reported stress whereas neuroticism was strongly associated with rumination, anxiety, and depression [75].

In contrast to neuroticism, individuals high in agreeableness, conscientiousness, and, to a lesser degree, extroversion can be expected to appraise everyday situations as less threatening and consequently experience lower degrees of day-to-day stress and hassle [76, 77]. Extroversion is a trait associated with an impulse toward sociability and assertiveness. Extroverted individuals are more likely to be selfassured and confident in their disposition. In addition to being outgoing and cheerful, extroverted individuals tend to appraise problems positively and engage in optimistic upbeat thinking [78]. Due to more expansive social support networks and interpersonal contacts, extroverted individuals are more likely to communicate feelings, thoughts, and experiences with others and engage in adaptive problem solving and planning. While exposed to a higher number of potential stressors, extroverted individuals deploy effective coping strategies and are therefore less prone to the negative impacts of stress and anxiety [79]. Connections have been made between extroversion and increased achievement on tasks inclusive of social interaction [80]. The trait of agreeableness reflects the regulation of interpersonal frustration and an orientation which seeks to avoid conflict and disagreement. From the perspective of task completion and achievement, agreeable individuals are thus best suited to social situations which require collaboration and cooperation. Agreeable individuals are considered flexible and accommodating of changes in circumstance, situation, and demand [81]. Agreeable individuals often demonstrate a desire to serve the needs of others through an inherently prosocial orientation which further includes expressions of altruism and sympathy [82].
Conscientiousness reflects a desire to accept responsibility and adhere to strict principles of conduct. Conscientious individuals are often purposeful, disciplined, and organized, particularly when focused on task achievement due to their intrinsic achievement motive [83]. The achievementfocused regulation of behavior among conscientious individuals also means that fluctuations in circumstance and external environment changes are likely to be successfully negotiated as the task competition and achievement motive are dominant. Furthermore, conscientious individuals are often rational decision makers [84] and deploy problemfocused and adaptive emotion-focused coping such as positive reframing and humor [85]. Conscientious individuals may experience fewer disruptions and less stress within their daily lives on account of having stable personalities [86]. Conscientiousness has also been linked to greater academic achievement outcomes $[87,88]$ as it encompasses organization, self-discipline, and determination.

Intellect (more commonly termed as openness) is associated with being imaginative, creative, and original [89] and having a preference for divergent thinking [90]. It has been defined as a trait which "reflects individual differences in the ability and tendency to seek, detect, comprehend, utilize, and appreciate complex patterns of information, both sensory and abstract" ([91]: 369). Several studies have made connections between intellect, critical thinking, and academic achievement outcomes [92, 93]. Individuals high in intellect tend to be open to fluctuations in circumstance and external environment changes, and due to broad learning experiences [94], such individuals can cope with stress through deployment of various adaptive strategies.

\section{Aims and Hypotheses}

Referenced within the specific context of the novel coronavirus pandemic and prohibitions on face-to-face contact within a Japanese university situation, the current research tests the hypothesis that $(\mathrm{H} 1)$ stress appraisals mediate the relationship between personality and the affordance of socially distanced online education. It is hypothesized that (H2) as adaptive personality traits, extroversion, agreeableness, conscientiousness, and intellect predict reduced generalized life stress appraisals; (H3) as a maladaptive personality trait, neuroticism predicts increased generalized life stress appraisals; (H4) generalized life stress appraisals predict increased online learning stress appraisals; and (H5) online learning stress appraisals predict a decrease in the affordance of socially distanced online education.

\section{Methods}

4.1. Participants and Context. The context of the current study is an information systems university in northern Japan. The university has approximately 1200 full-time undergraduate students. During the first semester of 2020, all lectures and classes were moved to an online only format with students prohibited from attending the university. All students therefore became socially distanced online learners located around Japan. While many students subsequently 
experienced an undergraduate education delivered through the Moodle learning management system, in the absence of internal quality assurances, individual teachers were permitted to implement methods and materials of their own choosing. The undergraduate student populations were therefore exposed to a broad range of delivery methods and materials dependent upon individual course teacher. After 30 weeks of learning under such conditions, all first- and second-year students were contacted by the author, and voluntary participation in the current study was invited. Students were given a brief overview of the study, and consenting students were directed to an online Japanese instrument comprising of the measures outlined below. After a period of one month, a total of 293 complete responses were gathered. The sample included 58 female students and 235 male students with a mean age of 19.6 years old $(\mathrm{SD}=0.72)$.

\subsection{Measures}

4.2.1. Personality. The lexical tradition of personality trait assessment utilizes adjectives to represent behavioral tendencies, either as standalone descriptors or as pairs of behavioral opposites. These measures have been critiqued for the influence of temporal mood states on lexical choice in addition to ignoring the meaning of those adjectives not selected. Complete sentences have the advantage of being semantically and context-specific although measures such as the NEO-PI-R require a significant level of literacy and are thus at risk from introducing response error [95]. The current study used a Japanese translation of the 50 -item IPIP representation of the Goldberg [96] markers for the five-factor structure (IPIP-BFM-50). The IPIP-BFM-50 retains a focus on assessment in the lexical tradition while overcoming the limitations of binary adjectives and elaborate sentences. The measure is inclusive of ten indicators on each personality trait including extroversion, agreeableness, conscientiousness, neuroticism, and intellect. Items are assessed on a five-point scale ranging from "very accurate" (5) to "very inaccurate" (1) and are distributed in nonconsecutive order. An initial confirmatory factor analysis (CFA) of the fivefactor personality model returned a poor fit $\left(\chi^{2}=3074.567\right.$ $(\mathrm{df}=1165), \quad p \leq 0.001, \quad \mathrm{NC}=2.639, \quad \mathrm{TLI}=0.619, \quad \mathrm{CFI}=$ 0.638 , and RMSEA $=0.075$ ). Several of the indicators on each of the five personality traits returned standardized loadings below the recommended cut-off of 0.60 [97]. These indicators were removed leaving a total of 17 reliable indicators across the five personality traits. The retested measurement model returned an improved goodness of fit $\left(\chi^{2}=214.253 \quad(\mathrm{df}=109), \quad p \leq 0.001, \quad \mathrm{NC}=1.966, \quad \mathrm{TLI}=\right.$ $0.932, \mathrm{CFI}=0.945$, and RMSEA $=0.058)$.

4.2.2. Stress. The Perceived Stress Scale (PSS) is a short measure which assesses the degree to which certain life situations are appraised as stressful [98]. The original measure uses 14 questions and asks participants to consider their thoughts and feelings in relation to how often certain feelings have arisen during a specific period. Using the PSS as a start point, a two-factor ten-item Japanese measure was devised which assessed generalized life stress and online learning stress referenced to the prior few months of daily life and study during the novel coronavirus pandemic. Items were presented to participants as questions answerable on a fivepoint frequency scale ranging from "very often" (5) to "never" (1). On the generalized life stress factor, three items referred to how often participants had felt unable to control important things in their life were frustrated by problems in their life and unable to overcome difficulties in their life while two further items referred to how often participants had felt alone and angry about their current life situation. For the online learning stress factor, the five items referred to how often participants had felt upset, stressed, confused, demotivated, and alone because of something that had happened on one of their socially distanced online courses at the university. An initial CFA of the two-factor stress model returned a poor fit $\left(\chi^{2}=231.488(\mathrm{df}=34), p \leq 0.001, \mathrm{NC}\right.$ $=6.808, \mathrm{TLI}=0.818, \mathrm{CFI}=0.863$, and $\mathrm{RMSEA}=0.141)$. One indicator from each of the two-factors returned a standardized loading below the recommended cut-off of 0.60 [97] and was therefore removed. The retested model returned an acceptable goodness of fit $\left(\chi^{2}=63.581\right.$ $(\mathrm{df}=19), p \leq 0.001, \mathrm{NC}=3.346, \mathrm{TLI}=0.942, \mathrm{CFI}=0.960$, and RMSEA $=0.090)$.

\subsubsection{Affordance of Socially Distanced Online Education.} From an information communication technology perspective, Zhang [63] proposes a motivational affordance framework inclusive of principles such as autonomy and the self (supporting autonomy and opportunities for the representation of self-identity), competence and achievement (design for optimal challenge and the provision of positive and timely feedback), relatedness (facilitate interpersonal interaction and represent human social bonds), leadership and followership (facilitate a desire to influence others and a desire to be influenced by others), and affect and emotion (induce emotions via short- and long-term exposure to the technology). From an educational perspective, several affordances have been proposed as applicable to learning online such as the need to provide maximum flexibility to technology users [99], the need to provide opportunities for interactive dialogues between students and teachers relative to the teaching materials [100], and the need to provide opportunities for students to progress from the level of novice to expert [101]. In the current study, seven Japanese statements were presented to participants on a five-point scale ranging from "strongly agree" (5) to "strongly disagree" (1). The statements asked participants to appraise their experience of socially distanced online education over the past 30 weeks relative to encouraging personal learning responsibility, as helping develop time management skills, as promoting active participation and successful communication, as satisfying educational needs, as offering flexibility, and as promoting a positive educational experience. An initial CFA of the single-factor online learning affordance model returned a poor fit $\left(\chi^{2}=89.264(\mathrm{df}=14), p \leq 0.001, \mathrm{NC}=6.376\right.$, $\mathrm{TLI}=0.837, \mathrm{CFI}=0.891$, and RMSEA $=0.136$ ). Three indicators returned standardized loadings below the recommended cut-off of 0.60 [97]. These indicators were therefore removed. The retested measurement model 
returned an improved goodness of fit $\left(\chi^{2}=2.331(\mathrm{df}=2)\right.$, $p \geq 0.05, \quad \mathrm{NC}=1.166, \quad \mathrm{TLI}=0.998, \quad \mathrm{CFI}=0.999, \quad$ and RMSEA $=0.024)$.

\section{Analysis and Results}

The descriptive statistics drawn from the retained indicators are shown in Table 1.

Table 2 shows the reliability and validity attributes in addition to bivariate correlations. Cronbach's alpha values for the six constructs were either good $(>0.80)$ or acceptable $(>0.70)$ [102]. Construct validity was affirmed through average variance extracted (AVE) values of $>0.50$ combined with composite reliability values $>0.70$ [103]. The discriminant validity of the data was confirmed through assessing whether the square root of the AVE was greater than the off-diagonal correlations. The absence of significant correlations between the five-factor personality traits and the affordance of socially distanced online education suggests that a mediated relationship through the two-factor stress component can be tested.

The most prevalent personality traits in the current sample were neuroticism $(M=3.45, \mathrm{SD}=0.99)$ and agreeableness $(M=3.28, \quad \mathrm{SD}=0.88)$ although no significant correlation was found between them suggesting that they exert influence in isolation. The other most dominant personality traits were extroversion $(M=2.86, \mathrm{SD}=0.89)$, conscientiousness $(M=2.76, \mathrm{SD}=0.99)$, and intellect $(M=2.76$ , $\mathrm{SD}=0.90)$. Extroversion had significant positive correlations with agreeableness and intellect in addition to a significant negative correlation with neuroticism. Agreeableness had a significant positive correlation with intellect. Conscientiousness had a significant negative correlation with neuroticism. Neuroticism also had a significant negative correlation with extroversion and intellect. Although gender differences were not a focal point in the current study, a oneway analysis of variance (ANOVA) found significant personality trait differences on neuroticism $(F(1,291)=15.816, p \leq 0.001)$ and generalized life stress $(F(1,291)=9.526, p \leq 0.01)$ with female students having significantly higher values on both measures. No significant differences were found relative to age.

Structural equation modeling with IBM SPSS AMOS 27 was used to devise and test the hypotheses. The $\chi^{2}$ (chisquare), NC (normed chi-square), TLI (Tucker-Lewis index), CFI (comparative fit index), and RMSEA (root mean square error of approximation) were selected as the fit criteria. A preliminary model assessing the relationship between personality and the criterion variable revealed no significant direct effects, thus indicating that it was appropriate to further test for mediation through the two-factor stress variable. The two-factor stress variable was modelled as a serial interaction with generalized life stress (superordinate category) believed to be predictive of online learning stress (subordinate category). Subsequent models therefore used bootstrapping (2000 samples, 95\% CI) (bias-corrected confidence estimates) [104] to test for mediation. The initially tested full structural model returned an acceptable goodness of fit $\left(\chi^{2}=653.665(\mathrm{df}=360), p \leq 0.001, \mathrm{NC}=\right.$
$1.824, \mathrm{TLI}=0.911, \mathrm{CFI}=0.921$, and RMSEA $=0.053)$ which accounted for $31.3 \%$ of the variance in the criterion variable (Table 3).

As part of the retrimming process, insignificant paths and variables were removed, and a direct path was inserted between extroversion and online learning stress and between neuroticism and online learning stress. The retrimmed full structural model returned a slightly improved fit $\left(\chi^{2}=421.021 \quad(\mathrm{df}=221), \quad p \leq 0.001, \quad \mathrm{NC}=1.905, \quad \mathrm{TLI}=\right.$ $0.923, \mathrm{CFI}=0.933$, and RMSEA $=0.056$ ). This rested model accounted for $31.6 \%$ of the variance in the criterion variable (Table 4).

The retrimmed structural model is shown in Figure 1.

\section{Discussion}

Referenced within the specific context of the novel coronavirus pandemic and prohibitions on face-to-face contact within a Japanese university situation, the current research tested the primary hypothesis that (H1) stress appraisals mediate the relationship between personality and the affordance of socially distanced online education. The hypothesis has been partially accepted in relation to the functioning of conscientiousness and neuroticism. The retrimmed structural model indicates that conscientiousness had a positive impact on the affordance of socially distanced online education when mediated through generalized life stress and online learning stress. This outcome supports the promotion of thoughts and behaviors underpinned by aspects of conscientiousness for two reasons. First, conscientiousness provides a channel through which online education can be appraised in a more positive manner; however, this would appear conditional on the opportunities afforded within a particular online experience for students to express conscientiousness as reward bearing (e.g., time management in meeting an assignment deadline, in being required to create and execute a plan of study). This draws attention to the issue of quality assurance, standardization, and the need for institutions to have a coherent plan of action and accountability. Second, thoughts and behaviors underpinned by aspects of conscientiousness provide a means to mitigate stress appraisals within daily life (partial acceptance of H2) and within the online learning environment.

Within the context of education, conscientious thoughts and behaviors can be conceptualized through reference to self-regulation as a "constructive process whereby learners set goals for their learning and then attempt to monitor, regulate, and control their cognition, motivation, and behaviour, guided and constrained by their goals and the contextual features in the environment" ([105]: 453). Conscientiousness is therefore a personality trait which lends itself to the main principles of self-regulation. Selfregulation can provide teachers and students with an achievement-focused framework to mitigate stress appraisals and promote the affordance of socially distanced online education. A recent study into online education provides support for this proposition in detailing how the level of selfregulation within a learning initiative determines stress, meaning that students who are poor self-regulators also 
TABle 1: Descriptive statistics of retained indicators.

\begin{tabular}{|c|c|c|c|c|c|c|}
\hline \multirow{2}{*}{ Indicators } & \multicolumn{5}{|c|}{ Frequencies of responses $n(\%)$} & \multirow{2}{*}{$M(\mathrm{SD})$} \\
\hline & 5 & 4 & 3 & 2 & 1 & \\
\hline EXT1 & $9(3.1)$ & $65(22.2)$ & $93(31.7)$ & $73(24.9)$ & $53(18.1)$ & $2.67(1.10)$ \\
\hline EXT2 & $29(9.9)$ & $65(22.2)$ & $73(24.9)$ & $87(29.7)$ & $39(13.3)$ & $2.85(1.19)$ \\
\hline EXT3 & $20(6.8)$ & $67(22.9)$ & $76(25.9)$ & $89(30.4)$ & $41(14.0)$ & $2.78(1.14)$ \\
\hline EXT4* & $43(14.7)$ & $84(28.7)$ & $82(28)$ & $63(21.5)$ & $21(7.2)$ & $3.22(1.15)$ \\
\hline AGR1 & $31(10.6)$ & $98(39.2)$ & $71(24.2)$ & $68(23.2)$ & $25(8.5)$ & $3.14(1.14)$ \\
\hline AGR2 & $23(7.8)$ & $115(39.2)$ & $77(26.3)$ & $66(22.5)$ & $12(4.1)$ & $3.24(1.02)$ \\
\hline AGR3* & $48(16.4)$ & $110(37.5)$ & $80(27.3)$ & $40(13,7)$ & $15(5.1)$ & $3.46(1.07)$ \\
\hline CON1 & $31(10.6)$ & $67(22.9)$ & $62(21.2)$ & $94(32.1)$ & $39(13.3)$ & $2.85(1.22)$ \\
\hline CON2 & $21(7.2)$ & $49(16.7)$ & $53(18.1)$ & $103(35.2)$ & $67(22.9)$ & $2.50(1.21)$ \\
\hline $\mathrm{CON} 3 *$ & $27(9.2)$ & $64(21.8)$ & $97(33.1)$ & $70(23.9)$ & 35 (11.9) & $2.92(1.14)$ \\
\hline NEU1* & 45 (15.4) & $92(31.4)$ & $71(24.2)$ & $64(21.8)$ & $21(7.2)$ & $3.25(1.17)$ \\
\hline NEU2 & $82(28)$ & $112(38.2)$ & $43(14.7)$ & 40 (13.7) & $16(5.5)$ & 3.69 (1.17) \\
\hline NEU3 & $53(18.1)$ & $103(35.2)$ & $69(23.5)$ & 46 (15.7) & $22(7.5)$ & $3.40(1.17)$ \\
\hline INT1 & $14(4.8)$ & $38(13)$ & $112(38.2)$ & $86(29.4)$ & $43(14.7)$ & $2.63(1.03)$ \\
\hline INT2 & $19(6.5)$ & $60(20.5)$ & $96(32.8)$ & $87(29.7)$ & $31(10.6)$ & $2.82(1.07)$ \\
\hline INT3* & $14(4.8)$ & $55(18.8)$ & $115(39.2)$ & $84(28.7)$ & $25(8.5)$ & $2.82(.98)$ \\
\hline GLS1 & $47(16)$ & $68(23.2)$ & $81(27.6)$ & $71(24.2)$ & $26(8.9)$ & $3.13(1.20)$ \\
\hline GLS2 & $23(7.8)$ & $69(23.5)$ & $101(34.5)$ & $75(25.6)$ & $25(8.5)$ & $2.96(1.07)$ \\
\hline GLS3 & $32(10.9)$ & $67(22.9)$ & $105(35.8)$ & $68(23.2)$ & $21(7.2)$ & 3.07 (1.08) \\
\hline GLS4 & $17(5.8)$ & $43(14.7)$ & $85(29)$ & $93(31.7)$ & $55(18.8)$ & $2.57(1.12)$ \\
\hline OLS1 & $23(7.8)$ & $59(20.1)$ & $105(35.8)$ & $81(27.6)$ & $25(8.5)$ & $2.91(1.06)$ \\
\hline OLS2 & $50(17.1)$ & $62(21.2)$ & 93 (31.7) & $61(20.8)$ & $27(9.2)$ & $3.16(1.20)$ \\
\hline OLS3 & 35 (11.9) & $80(27.3)$ & $106(36.2)$ & $53(18.1)$ & $19(6.5)$ & $3.20(1.07)$ \\
\hline OLS4 & $53(18.1)$ & $82(28)$ & $68(23.2)$ & $63(21.5)$ & $27(9.2)$ & $3.24(1.23)$ \\
\hline AOL1 & $33(11.3)$ & $99(33.8)$ & $68(23.2)$ & $63(21.5)$ & $30(10.2)$ & $3.14(1.18)$ \\
\hline AOL2 & $27(9.2)$ & $81(27.6)$ & $102(34.8)$ & $65(22.2)$ & $18(6.1)$ & $3.11(1.05)$ \\
\hline AOL3 & $38(13)$ & $86(29.4)$ & $93(31.7)$ & $53(18.1)$ & $23(7.8)$ & $3.21(1.12)$ \\
\hline AOL4 & $44(15)$ & $105(35.8)$ & $69(23.5)$ & $52(17.7)$ & $23(7.8)$ & $3.32(1.16)$ \\
\hline
\end{tabular}

Note: EXT: extroversion; AGR: agreeableness; CON: conscientiousness; NEU: neuroticism; INT: intellect; GLS: generalized life stress; OLS: online learning stress; AOL: affordance of socially distanced online education. * denotes reversed indicator.

TABLE 2: Overview of the variables.

\begin{tabular}{|c|c|c|c|c|c|c|c|c|c|c|c|c|c|}
\hline & \multirow{2}{*}{$M(\mathrm{SD})$} & \multirow{2}{*}{ CA } & \multirow{2}{*}{ AVE } & \multirow{2}{*}{ CR } & \multirow{2}{*}{ DV } & \multicolumn{8}{|c|}{ Pearson's correlation } \\
\hline & & & & & & EXT & AGR & $\mathrm{CON}$ & NEU & INT & GLS & OLS & $\mathrm{AOL}$ \\
\hline EXT & $2.86(0.89)$ & 0.83 & 0.50 & 0.83 & 0.70 & - & & & & & & & \\
\hline AGR & $3.28(0.88)$ & 0.75 & 0.54 & 0.77 & 0.73 & $0.29^{*}$ & - & & & & & & \\
\hline $\mathrm{CON}$ & $2.76(0.99)$ & 0.78 & 0.57 & 0.79 & 0.75 & 0.09 & 0.01 & - & & & & & \\
\hline NEU & $3.45(0.99)$ & 0.83 & 0.59 & 0.81 & 0.76 & $-0.29^{* *}$ & 0.05 & $-0.20^{* *}$ & - & & & & \\
\hline INT & $2.76(0.90)$ & 0.85 & 0.66 & 0.85 & 0.81 & $0.31^{* *}$ & $0.14^{*}$ & 0.08 & $-0.20^{* *}$ & - & & & \\
\hline GLS & $2.93(0.88)$ & 0.78 & 0.52 & 0.81 & 0.72 & $-0.13^{*}$ & 0.05 & $-0.25^{* *}$ & $0.42^{* *}$ & -0.07 & - & & \\
\hline OLS & $3.12(0.98)$ & 0.88 & 0.66 & 0.88 & 0.81 & 0.07 & 0.01 & -0.10 & $0.14^{* *}$ & -0.02 & $0.53^{* *}$ & - & \\
\hline $\mathrm{AOL}$ & $3.19(0.91)$ & 0.82 & 0.55 & 0.82 & 0.74 & -0.00 & 0.03 & 0.11 & -0.07 & 0.04 & $-0.40^{* *}$ & $-0.50^{* *}$ & - \\
\hline
\end{tabular}

Note: EXT: extroversion; AGR: agreeableness; CON: conscientiousness; NEU: neuroticism; INT: intellect; GLS: generalized life stress; OLS: online learning stress; AOL: affordance of socially distanced online education; M: mean; SD: standard deviation; CA: Cronbach's alpha; AVE: average variance extracted; CR: composite reliability; DV: discriminant validity. ${ }^{*} p \leq 0.05 ;{ }^{* *} p \leq 0.01$. 
TABLE 3: Initially tested direct and indirect effects.

\begin{tabular}{|c|c|c|c|c|c|c|c|}
\hline \multirow{2}{*}{\multicolumn{4}{|c|}{ Direct and indirect effects }} & \multirow{3}{*}{$\begin{array}{c}\text { Std. } \beta \\
0.04\end{array}$} & \multirow{3}{*}{$\begin{array}{c}\text { SE } \\
0.08\end{array}$} & \multicolumn{2}{|c|}{$95 \% \mathrm{CI}$} \\
\hline & & & & & & \multirow{2}{*}{$\frac{\text { Lower }}{-0.12}$} & \multirow{2}{*}{$\frac{\text { Upper }}{0.20}$} \\
\hline $\mathrm{EXT} \rightarrow$ & GLS & & & & & & \\
\hline $\mathrm{AGR} \rightarrow$ & GLS & & & -0.02 & 0.06 & -0.17 & 0.12 \\
\hline $\mathrm{CON} \rightarrow$ & GLS & & & $-0.17^{* *}$ & 0.05 & -0.33 & -0.02 \\
\hline $\mathrm{NEU} \rightarrow$ & GLS & & & $0.48^{* * *}$ & 0.08 & 0.32 & 0.64 \\
\hline \multirow[t]{3}{*}{$\mathrm{INT} \rightarrow$} & GLS & & & 0.03 & 0.06 & -0.11 & 0.18 \\
\hline & $\mathrm{GLS} \rightarrow$ & OLS & & $0.59^{* * *}$ & 0.08 & 0.46 & 0.71 \\
\hline & & OLS $\rightarrow$ & AOL & $-0.55^{* * *}$ & 0.06 & -0.65 & -0.44 \\
\hline $\mathrm{EXT} \rightarrow$ & GLS $\rightarrow$ & OLS $\rightarrow$ & $\mathrm{AOL}$ & -0.01 & 0.02 & -0.07 & 0.03 \\
\hline $\mathrm{AGR} \rightarrow$ & $\mathrm{GLS} \rightarrow$ & OLS $\rightarrow$ & $\mathrm{AOL}$ & 0.00 & 0.02 & -0.04 & 0.06 \\
\hline $\mathrm{CON} \rightarrow$ & $\mathrm{GLS} \rightarrow$ & $\mathrm{OLS} \rightarrow$ & $\mathrm{AOL}$ & $0.05^{*}$ & 0.02 & 0.00 & 0.12 \\
\hline $\mathrm{NEU} \rightarrow$ & $\mathrm{GLS} \rightarrow$ & OLS $\rightarrow$ & AOL & $-0.16^{* *}$ & 0.03 & -0.24 & -0.09 \\
\hline \multirow[t]{2}{*}{$\mathrm{INT} \rightarrow$} & $\mathrm{GLS} \rightarrow$ & OLS $\rightarrow$ & AOL & -0.01 & 0.02 & -06 & 0.03 \\
\hline & $\mathrm{GLS} \rightarrow$ & OLS $\rightarrow$ & $\mathrm{AOL}$ & $-0.33^{* *}$ & 0.05 & -0.45 & -0.23 \\
\hline
\end{tabular}

Note: EXT: extroversion; AGR: agreeableness; CON: conscientiousness; NEU: neuroticism; INT: intellect; GLS: generalized life stress; OLS: online learning stress; AOL: affordance of socially distanced online education. ${ }^{*} p$ $\leq 0.05,{ }^{* *} p \leq 0.01$, and ${ }^{* * *} p \leq 0.001$.

TABLE 4: Retrimmed direct and indirect effects.

\begin{tabular}{|c|c|c|c|c|c|c|c|}
\hline \multirow{2}{*}{\multicolumn{4}{|c|}{ Direct and indirect effects }} & \multirow{3}{*}{$\frac{\text { Std. } \beta}{0.15^{*}}$} & \multirow{3}{*}{$\begin{array}{c}\text { SE } \\
0.07\end{array}$} & \multicolumn{2}{|c|}{$95 \% \mathrm{CI}$} \\
\hline & & & & & & \multirow{2}{*}{$\frac{\text { Lower }}{0.01}$} & \multirow{2}{*}{$\begin{array}{c}\text { Upper } \\
0.29\end{array}$} \\
\hline $\mathrm{EXT} \rightarrow$ & & OLS & & & & & \\
\hline $\mathrm{CON} \rightarrow$ & GLS & & & $-0.16^{* *}$ & 0.05 & -0.32 & -0.01 \\
\hline \multirow{4}{*}{$\mathrm{NEU} \rightarrow$} & GLS & & & $0.49^{* * *}$ & 0.07 & 0.35 & 0.61 \\
\hline & & OLS & & $-0.17^{*}$ & 0.08 & -0.35 & 0.01 \\
\hline & GLS $\rightarrow$ & OLS & & $0.74^{* * *}$ & 0.11 & 0.57 & 0.88 \\
\hline & & OLS $\rightarrow$ & $\mathrm{AOL}$ & $-0.56^{* * *}$ & 0.06 & -0.66 & -0.45 \\
\hline $\mathrm{EXT} \rightarrow$ & & $\mathrm{OLS} \rightarrow$ & $\mathrm{AOL}$ & $-0.08^{*}$ & 0.04 & -0.16 & -0.00 \\
\hline $\mathrm{CON} \rightarrow$ & $\mathrm{GLS} \rightarrow$ & OLS $\rightarrow$ & $\mathrm{AOL}$ & $0.07^{*}$ & 0.03 & 0.00 & 0.14 \\
\hline \multirow{2}{*}{$\mathrm{NEU} \rightarrow$} & & $\mathrm{OLS} \rightarrow$ & $\mathrm{AOL}$ & $-0.10^{*}$ & 0.04 & -0.20 & -0.01 \\
\hline & $\mathrm{GLS} \rightarrow$ & $\mathrm{OLS} \rightarrow$ & $\mathrm{AOL}$ & $-0.41^{* *}$ & 0.06 & -0.56 & -0.29 \\
\hline
\end{tabular}

Note: EXT: extroversion; AGR: agreeableness; CON: conscientiousness; NEU: neuroticism; INT: intellect; GLS: generalized life stress; OLS: online learning stress; AOL: affordance of socially distanced online education. ${ }^{*} p$ $\leq 0.05,{ }^{* *} p \leq 0.01$, and ${ }^{* * *} p \leq 0.001$.

experience higher degrees of stress associated with the demands of learning [106]. As shown within the current study, heightened stress appraisals connected to learning are likely to have a negative impact on the affordance of socially distanced online education. Moreover, conscientiousness and self-regulated learning have been linked to greater academic achievement outcomes with more successful students having higher levels of conscientiousness and a more expansive repertoire of regulation strategies [87, 88, 107, 108].

Concerning the finding that neuroticism had a significant negative impact on the affordance of socially distanced online learning when mediated through generalized life stress and online learning stress appraisals, such a finding echoes much of what has been documented regarding the negative role of neuroticism. Neuroticism is known to promote the negative framing of experience [69, 70], the increased appraisal of stress within daily situations [71], and greater impulsivity and lack of control [72]. Reflecting a preference for avoidance-based coping strategies, neuroticism has further been linked to reduced test performance [109], reduced motivation to study [110], and increased absenteeism [111]. However, while conscientiousness and neuroticism are commonly understood as promoting contrary outcomes (i.e., one positive and one negative), beneficial instances of high conscientiousness and high neuroticism have been identified in relation to health behaviors [112]. Although neuroticism had an expected significant impact on generalized life stress (acceptance of H3) within the current study, there is partial evidence for a positive function of neuroticism in relation to its negative significant impact on online learning stress appraisal.

To understand this relationship, it is useful to also consider the relationship between extroversion and online learning stress appraisal in contrast. Extroverted individuals are typically energetic, sociable, lively, and assertive whereas neurotic individuals tend to be withdrawn, irritable, anxiety, moody, and self-conscious. The characteristics of online learning within the current study appear to lend themselves more toward neurotic students than toward extroverted students. As mentioned, previous studies have found that online learning causes stress and anxiety in some students due to a lack of direct social interaction with peers and teachers $[51,53]$. The outcome of the current study indicates that while there was no significant relationship between extroversion and generalized life stress appraisal, there was a significant direct relationship between extroversion and online learning stress appraisal with extroverted students having higher online learning stress appraisals than neurotic students. Within the current research context, online learning therefore offers some benefits to neurotic students such as a reduction in stress caused by the challenges of direct social interaction.

In contrast, the removal of direct social interaction opportunities in favor of a more solitary online learning experience creates stress for extroverted students. This finding should be of concern as the current study also found a strong negative relationship between online learning stress appraisal and the affordance of socially distanced online education (acceptance of $\mathrm{H} 5$ ). To better satisfy extroverted students, online learning initiatives are therefore encouraged to provide direct social interaction opportunities while also retaining opportunities-but not rewards-for more isolated activities which favor more neurotic students. Finally, the appraisal of generalized life stress functioned as a positive indicator of the appraisal of online learning stress (acceptance of H4) which provides evidence to support the idea that the stressors of daily life relating to the pandemic influence stress appraisals within an online learning situation. 


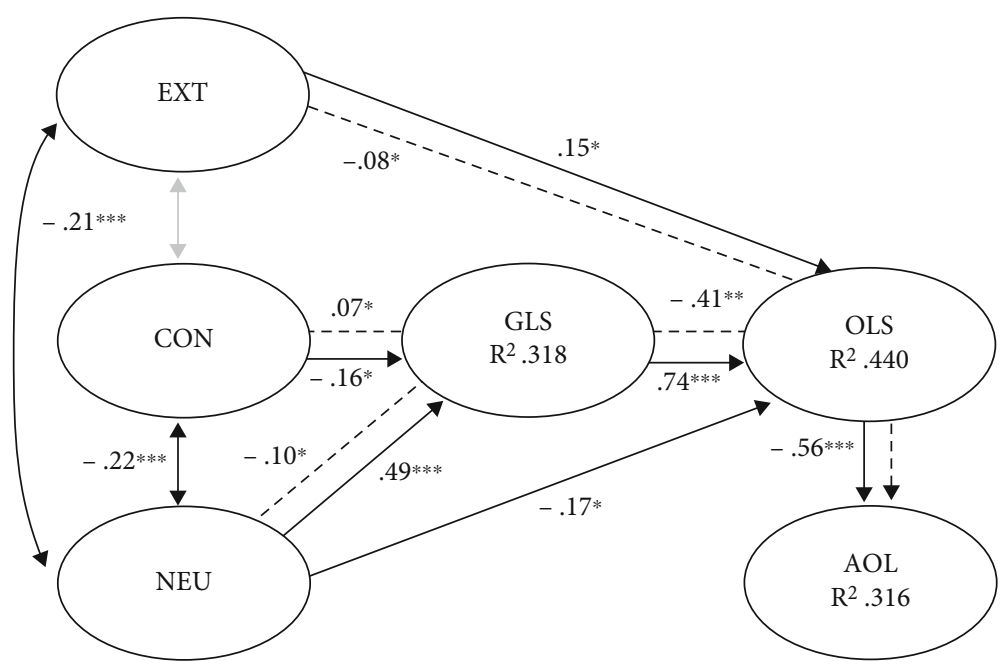

FIGURE 1: The retrimmed structural model $\left(\chi^{2}=421.021(\mathrm{df}=221), p \leq 0.001, \mathrm{NC}=1.905, \mathrm{TLI}=0.923, \mathrm{CFI}=0.933\right.$, and RMSEA $\left.=0.056\right)$. Full lines denote direct paths while broken lines indicate indirect paths. ${ }^{*} p \leq 0.05,{ }^{* *} p \leq 0.01$, and ${ }^{* * *} p \leq 0.001$.

\section{Conclusion}

As a proactive teacher-researcher response to the dramatic changes experienced surrounding the novel coronavirus pandemic, the current study has focused on the shift toward the provision of socially distanced online education within the context of a Japanese information systems university. Attention has been given to the impact of personality traits on the affordance of socially distanced online education mediated through generalized life stress and online learning stress appraisal. While personality traits are relatively stable across the lifespan, the current study suggests that teachers should make structured efforts to promote the principles of conscientiousness through self-regulation. Conscientiousness within the current student sample promoted positive outcomes although, and perhaps reflecting the fact that the research context is a nonelite university, conscientiousness was found to be the equal weakest personality trait alongside intellect. Moreover and of concern is the fact that neuroticism and agreeableness were found to be the most prevalent traits within the sample population. Therefore, the author amplifies the view that "university students must be trained in selfregulated learning behaviours and made aware of the pitfalls of a lack of regulation or dysregulation in one's learning" ([106]: 11). This guidance is given further significance through research highlighting links between self-regulation and academic achievement in online environments $[113,114]$. If a socially distanced student population is low in conscientiousness and intellect (and high in neuroticism and agreeableness), then it is imperative for teachers to promote conscientious behaviors through a framework of self-regulation. It is further necessary to structure online educational provisions in a manner which rewards conscientious actions as dictated via the principles of positive self-regulation (e.g., time management, strategic planning, goal setting, and help seeking).

While the model tested in the current study has produced several outcomes which can be used to better inform suitable teaching pedagogies, within the boundaries of Japa- nese higher education, these have little chance of implementation beyond the initiatives of individual teachers due to institutional and academic inertia. It has been documented how Japanese universities were poorly prepared for the switch to the provision of online education at such short notice [35-37]. Although restrictions surrounding the pandemic caught many nations off-guard, the nature of Japan's lack of preparedness reflects characteristics innate to the education system itself. These include an absence of quality assurances relating to faculty competencies and qualifications, an absence of accountability for poor teaching materials and syllabus designs, and a lack of direction concerning standardization and assessment practices. Relative to these concerns, a recent exploration of online self-regulation within context cautions how "the re-designing of face-to-face course materials within the current landscape requires conceptual and philosophical reflection about the nature of teaching and learning, stakeholder roles and the relationship between teachers, learners and teaching materials within digital learning communities" [115]. In a landscape of diminished academic accountability, normalized via a cultural imperative for conflict avoidance, such information is easily dismissed. In times of socially distanced online education, possessing academic knowledge relevant to the needs of students alongside the professional competencies required to deliver effective teaching solutions is paramount to a generation of students who have missed out on a traditional university experience.

\section{Data Availability}

The quantitative data used to support the findings of this study have not been made available due to the nature of participant consent.

\section{Ethical Approval}

Ethical approval was not required by the research institution due to the nature of the research. 


\section{Consent}

All participants were informed about the content of the research and that their participation was voluntary and subject to no conditions or agreements. Participants were further informed that individual data would not be disclosed while cumulative data would be used for the purpose of research and publication.

\section{Conflicts of Interest}

The author declares no conflict of interest.

\section{References}

[1] G. Arslan, M. Yıldırım, A. Tanhan, M. Buluş, and K. A. Allen, "Coronavirus stress, optimism-pessimism, psychological inflexibility, and psychological health: psychometric properties of the coronavirus stress measure," International Journal of Mental Health and Addiction, vol. 19, no. 6, pp. 1-17, 2020.

[2] N. E. Charles, S. J. Strong, L. C. Burns, M. R. Bullerjahn, and K. M. Serafine, "Increased mood disorder symptoms, perceived stress, and alcohol use among college students during the COVID-19 pandemic," Psychiatry Research, vol. 296, article 113706, 2021.

[3] R. Rossi, V. Socci, D. Talevi et al., "COVID-19 pandemic and lockdown measures impact on mental health among the general population in Italy," Frontiers in Psychiatry, vol. 11, p. 790, 2020.

[4] N. Salari, A. Hosseinian-Far, R. Jalali et al., "Prevalence of stress, anxiety, depression among the general population during the COVID-19 pandemic: a systematic review and metaanalysis," Globalization and Health, vol. 16, no. 1, p. 57, 2020.

[5] X. Wang, S. Hegde, C. Son, B. Keller, A. Smith, and F. Sasangohar, "Investigating mental health of US college students during the COVID-19 pandemic: cross-sectional survey study," Journal of Medical Internet Research, vol. 22, no. 9, article e22817, 2020.

[6] D. Lecic-Tosevski, O. Vukovic, and J. Stepanovic, "Stress and personality," Psychiatrike = Psychiatriki, vol. 22, no. 4, pp. 290-297, 2011.

[7] R. S. Lazarus, Psychological Stress and the Coping Process, McGraw-Hill, 1966.

[8] R. S. Lazarus, "Coping theory and research: past, present, and future," Psychosomatic Medicine, vol. 55, no. 3, pp. 234-247, 1993.

[9] R. S. Lazarus and S. Folkman, Stress, Appraisal, and Coping, Springer, 1984.

[10] D. R. Byrd and K. J. McKinney, "Individual, interpersonal, and institutional level factors associated with the mental health of college students," Journal of American College Health, vol. 60, no. 3, pp. 185-193, 2012.

[11] S. Grant and J. Langan-Fox, "Personality and the occupational stressor-strain relationship: the role of the big five," Journal of Occupational Health Psychology, vol. 12, no. 1, pp. 20-33, 2007.

[12] V. A. Horsburgh, J. A. Schermer, L. Veselka, and P. A. Vernon, "A behavioural genetic study of mental toughness and personality," Personality and Individual Differences, vol. 46, no. 2, pp. 100-105, 2009.
[13] Z. Liu, R. Liu, Y. Zhang et al., "Association between perceived stress and depression among medical students during the outbreak of COVID-19: the mediating role of insomnia," Journal of Affective Disorders, vol. 292, pp. 89-94, 2021.

[14] M. Vollrath, "Personality and stress," Scandinavian Journal of Psychology, vol. 42, no. 4, pp. 335-347, 2001.

[15] J. F. Ebstrup, L. F. Eplov, C. Pisinger, and T. Jørgensen, "Association between the five factor personality traits and perceived stress: is the effect mediated by general self-efficacy?," Anxiety, Stress, and Coping, vol. 24, no. 4, pp. 407419, 2011.

[16] D. Watson and L. A. Clark, "Negative affectivity: the disposition to experience aversive emotional states," Psychological Bulletin, vol. 96, no. 3, pp. 465-490, 1984.

[17] R. E. Laukkonen, J. M. Leggett, R. M. Gallagher et al., "Future of education and skills 2030: conceptual learning framework," in 8th Informal Working Group (IWG) Meeting 2931.OECD Conference Centre, Paris, France, 2018.

[18] The Japan Times, "COVID-19 pushes 1,300 Japanese university students to drop out," 2021, https://www.japantimes.co .jp/news/2021/02/28/national/university-students-dropout/.

[19] W. Cao, Z. Fang, G. Hou et al., "The psychological impact of the COVID-19 epidemic on college students in China," Psychiatry Research, vol. 287, article 112934, 2020.

[20] W. E. Copeland, E. McGinnis, Y. Bai et al., "Impact of COVID-19 pandemic on college student mental health and wellness," Journal of the American Academy of Child and Adolescent Psychiatry, vol. 60, no. 1, pp. 134-141.e2, 2021.

[21] S. A. Goppert and M. Pfost, "Undergraduate students' perceived stress levels in summer term 2020: a comparison to preceding academic terms," Frontiers in Psychology, vol. 12, article 672783, 2021.

[22] M. A. Islam, S. D. Barna, H. Raihan, M. N. A. Khan, and M. T. Hossain, "Depression and anxiety among university students during the COVID-19 pandemic in Bangladesh: a web-based cross-sectional survey," PLoS One, vol. 15, no. 8, article e0238162, 2020.

[23] Q. Liu and Z. Wang, "Perceived stress of the COVID-19 pandemic and adolescents' depression symptoms: the moderating role of character strengths," Personality and Individual Differences, vol. 182, article 111062, 2021.

[24] K. Parthiban, D. Pandey, and B. K. Pandey, "Impact of SARS$\mathrm{CoV}-2$ in online education, predicting and contrasting mental stress of young students: a machine learning approach," Augmented Human Research, vol. 6, no. 1, p. 10, 2021.

[25] B. Radwan, A. Yanez Touzet, S. Hammami, and D. Chaudhury, "Prolonged exposure to social stress impairs homeostatic sleep regulation," Frontiers in Neuroscience, vol. 15, article 633955, 2021.

[26] M. M. Ruissen, H. Regeer, C. P. Landstra et al., "Increased stress, weight gain and less exercise in relation to glycemic control in people with type 1 and type 2 diabetes during the COVID-19 pandemic," BMJ Open Diabetes Research \& Care, vol. 9, no. 1, article e002035, 2021.

[27] Q. Zheng, X. Lin, L. He, T. Freudenreich, and T. Liu, "Impact of the perceived mental stress during the COVID-19 pandemic on medical students' loneliness feelings and future career choice: a preliminary survey study," Frontiers in Psychiatry, vol. 12, article 666588, 2021.

[28] B. Bernal-Morales, J. F. Rodríguez-Landa, and F. Pulido-Criollo, "Impact of anxiety and depression symptoms on scholar 
performance in high school and university students, a fresh look at anxiety disorders," IntechOpen., 2015.

[29] R. Bruffaerts, P. Mortier, G. Kiekens et al., "Mental health problems in college freshmen: prevalence and academic functioning," Journal of Affective Disorders, vol. 225, pp. 97-103, 2018.

[30] J. Humensky, S. A. Kuwabara, J. Fogel, C. Wells, B. Goodwin, and B. W. Van Voorhees, "Adolescents with depressive symptoms and their challenges with learning in school," Journal of School Nursing, vol. 26, no. 5, pp. 377-392, 2010.

[31] A. Hysenbegasi, S. L. Hass, and C. R. Rowland, "The impact of depression on the academic productivity of university students," Journal of Mental Health Policy and Economics, vol. 8, no. 3, pp. 145-151, 2005.

[32] M. C. Pascoe, S. E. Hetrick, and A. G. Parker, "The impact of stress on students in secondary school and higher education," International Journal of Adolescence and Youth, vol. 25, no. 1, pp. 104-112, 2020.

[33] J. H. Amirkhan, G. K. Bowers, and C. Logan, “Applying stress theory to higher education: lessons from a study of first-year students," Studies in Higher Education, vol. 45, no. 11, pp. 2231-2244, 2020.

[34] C. Rapanta, L. Botturi, P. Goodyear, L. Guàrdia, and M. Koole, "Online university teaching during and after the Covid-19 crisis: refocusing teacher presence and learning activity," Postdigital Science and Education, vol. 2, no. 3, pp. 923-945, 2020.

[35] J. J. O’ Donoghue, “In era of COVID-19, a shift to digital forms of teaching in Japan. The Japan Times," 2020, https://www.japantimes.co.jp/news/2020/04/21/national/ traditional-to-digital-teaching-coronavirus/.

[36] K. Shoji, "Japan's students struggle to embrace online learning amid COVID-19. The Japan Times," 2020, https://www .japantimes.co.jp/news/2020/11/07/national/media-national/ students-online-coronavirus/.

[37] S. Yamamoto, "Coronavirus crisis shows Japan lagging in online education. NHK WORLD-JAPAN," 2020, https:// www3.nhk.or.jp/nhkworld/en/news/backstories/1137/.

[38] MEXT, "Education in Japan beyond the crisis of COVID-19," 2020, https://www.mext.go.jp/en/content/20200904_mxt_ kouhou01-000008961_1.pdf.

[39] J. M. Bachnik, Roadblocks on the Information Highway, Lexington Books, 2003.

[40] C. Latchem, I. Jung, K. Aoki, and A. E. Ozkul, "The tortoise and the hare enigma in e-transformation in Japanese and Korean higher education," British Journal of Educational Technology, vol. 39, no. 4, pp. 610-630, 2008.

[41] T. Barnett, A. W. Pearson, R. Pearson, and F. W. Kellermanns, "Five-factor model personality traits as predictors of perceived and actual usage of technology," European Journal of Information Systems, vol. 24, no. 4, pp. 374-390, 2015.

[42] S. Devaraj, R. Easley, and J. Crant, "Research note-how does personality matter? Relating the five-factor model to technology acceptance and use," Information Systems Research, vol. 19, no. 1, pp. 93-105, 2008.

[43] D. J. Rivers, "The role of personality traits and online academic self-efficacy in acceptance, actual use and achievement in Moodle," Education and Information Technologies, vol. 26, no. 4, pp. 4353-4378, 2021.

[44] G. B. Svendsen, J. A. Johnsen, K. L. Almas-Sorensen, and J. Vitterso, "Personality and technology acceptance: the influ- ence of personality factors on the core constructs of the technology acceptance model," Behaviour \& Information Technology, vol. 32, no. 4, pp. 323-334, 2013.

[45] V. Terzis, C. N. Moridis, and A. A. Economides, "How student's personality traits affect computer based assessment acceptance: integrating BFI with CBAAM," Computers in Human Behavior, vol. 28, no. 5, pp. 1985-1996, 2012.

[46] A. Essadek and T. Rabeyron, "Mental health of French students during the Covid-19 pandemic," Journal of Affective Disorders, vol. 277, pp. 392-393, 2020.

[47] C. K. Kaparounaki, M. E. Patsali, D. V. Mousa, E. Papadopoulou, K. Papadopoulou, and K. N. Fountoulakis, "University students' mental health amidst the COVID-19 quarantine in Greece," Psychiatry Research, vol. 290, article 113111, 2020.

[48] M. J. Savage, P. J. Hennis, D. Magistro, J. Donaldson, L. C. Healy, and R. M. James, "Nine months into the COVID-19 pandemic: a longitudinal study showing mental health and movement behaviours are impaired in UK students," International Journal of Environmental Research and Public Health, vol. 18, no. 6, p. 2930, 2021.

[49] K. Chinna, S. Sundarasen, H. B. Khoshaim et al., "Psychological impact of COVID-19 and lock down measures: an online cross-sectional multicounty study on Asian university students," PLoS One, vol. 16, no. 8, article e0253059, 2021.

[50] J. Wang, W. Liu, Y. Zhang, S. Xie, and B. Yang, "Perceived stress among Chinese medical students engaging in online learning in light of COVID-19," Psychology Research and Behavior Management, vol. Volume 14, pp. 549-562, 2021.

[51] A. Babicka-Wirkus, L. Wirkus, K. Stasiak, and P. Kozłowski, "University students' strategies of coping with stress during the coronavirus pandemic: data from Poland," PLoS One, vol. 16, no. 7, article e0255041, 2021.

[52] M. Wosnitza and S. Volet, "Origin, direction and impact of emotions in social online learning," Learning and Instruction, vol. 15, no. 5, pp. 449-464, 2005.

[53] A. R. Artino and K. D. Jones, "Exploring the complex relations between achievement emotions and self- regulated learning behaviors in online learning," The Internet and Higher Education, vol. 15, no. 3, pp. 170-175, 2012.

[54] N. Grishchenko, "The gap not only closes: resistance and reverse shifts in the digital divide in Russia," Telecommunications Policy, vol. 44, no. 8, pp. 102004-102015, 2020.

[55] S. Lemola, N. Perkinson-Gloor, S. Brand, J. F. Dewald-Kaufmann, and A. Grob, “Adolescents' electronic media use at night, sleep disturbance, and depressive symptoms in the smartphone age," Journal of Youth and Adolescence, vol. 44, no. 2, pp. 405-418, 2015.

[56] N. Mheidly, M. Y. Fares, and J. Fares, "Coping with stress and burnout associated with telecommunication and online learning," Frontiers in Public Health, vol. 8, article 574969, 2020.

[57] P. Tempski, F. M. Arantes-Costa, R. Kobayasi et al., "Medical students' perceptions and motivations during the COVID-19 pandemic," PLoS One, vol. 16, no. 3, article e0248627, 2021.

[58] T. Chen, L. Peng, X. Yin, J. Rong, J. Yang, and G. Cong, "Analysis of user satisfaction with online education platforms in China during the COVID-19 pandemic," Healthcare, vol. 8, no. 3, p. 200, 2020.

[59] I. Esteban-Millat, F. J. Martinez-Loopez, M. Pujol-Jover, J. C. Gaazquez-Abad, and A. Alegret, "An extension of the 
technology acceptance model for online learning environments," Interactive Learning Environments, vol. 26, no. 7, pp. 895-910, 2018.

[60] I. F. Liu, M. C. Chen, Y. S. Sun, D. Wible, and C. H. Kuo, "Extending the TAM model to explore the factors that affect intention to use an online learning community," Computers \& Education, vol. 54, no. 2, pp. 600-610, 2010.

[61] J. Gibson, The Ecological Approach to Visual Perception, Houghton Mifflin, 1979.

[62] P. Kirschner, J. Strijbos, K. Kreijns, and P. J. Beers, "Designing electronic collaborative learning environments," Educational Technology Research and Development, vol. 52, no. 3, pp. 47-66, 2004.

[63] P. Zhang, "Technical opinion motivational affordances," Communication of the ACM, vol. 51, no. 11, pp. 145-147, 2008.

[64] M. S. Chmielewski and T. A. Morgan, "Five-factor model of personality," in Encyclopedia of Behavioral Medicine, M. D. Gellman and J. R. Turner, Eds., Springer, 2013.

[65] J. M. Digman, "Personality structure: emergence of the fivefactor model," Annual Review of Psychology, vol. 41, no. 1, pp. 417-440, 1990.

[66] M. H. Olesen, D. K. Thomsen, A. Schnieber, and J. Tonnesvang, "Distinguishing general causality orientations from personality traits," Personality and Individual Differences, vol. 48, no. 5, pp. 538-543, 2010.

[67] P. T. Costa Jr. and R. R. McCrae, "The five-factor model of personality and its relevance to personality disorders," Journal of Personality Disorders, vol. 6, no. 4, pp. 343-359, 1992.

[68] K. C. Gunthert, L. H. Cohen, and S. Armeli, "The role of neuroticism in daily stress and coping," Journal of Personality and Social Psychology, vol. 77, no. 5, pp. 1087-1100, 1999.

[69] A. Delongis, D. Lee-Baggley, and M. Preece, "Coping with interpersonal stress: role of big five traits," Journal of Personality, vol. 73, no. 5, pp. 1141-1180, 2005.

[70] R. R. McCrae and P. T. Costa Jr., "The five-factor theory of personality," in Handbook of Personality: Theory and Research, O. P. John, R. W. Robins, and L. A. Pervin, Eds., pp. 159-181, The Guilford Press, 2008.

[71] K. W. Müller, M. E. Beutel, B. Egloff, and K. Wölfling, "Investigating risk factors for Internet gaming disorder: a comparison of patients with addictive gaming, pathological gamblers and healthy controls regarding the big five personality traits," European Addiction Research, vol. 20, no. 3, pp. 129-136, 2014.

[72] H. Afshar, H. R. Roohafza, A. H. Keshteli, M. Mazaheri, A. Feizi, and P. Adibi, "The association of personality traits and coping styles according to stress level," Journal of Research in Medical Sciences, vol. 20, no. 4, pp. 353-358, 2015.

[73] H. Hills and N. Norvell, "An examination of hardiness and neuroticism as potential moderators of stress outcomes," Behavioral Medicine, vol. 17, no. 1, pp. 31-38, 1991.

[74] Z. Alizadeh, A. Feizi, M. Rejali, H. Afshar, A. H. Keshteli, and P. Adibi, "The predictive value of personality traits for psychological problems (stress, anxiety and depression): results from a large population based study," Journal of Epidemiology and Global Health, vol. 8, no. 3-4, pp. 124-133, 2018.

[75] M. Ervasti, J. Kallio, I. Määttänen, J. Mäntyjärvi, and M. Jokela, "Influence of personality and differences in stress processing among Finnish students on interest to use a mobile stress management app: survey study," JMIR Mental Health, vol. 6, no. 5, article e10039, 2019.
[76] A. Bibbey, D. Carroll, T. J. Roseboom, A. C. Phillips, and S. R. de Rooij, "Personality and physiological reactions to acute psychological stress," International Journal of Psychophysiology, vol. 90, no. 1, pp. 28-36, 2013.

[77] M. Vollrath, D. Knoch, and L. Cassano, "Personality, risky health behaviour, and perceived susceptibility to health risks," European Journal of Personality, vol. 13, no. 1, pp. 39-50, 1999.

[78] A. B. Bakker, H. van Emmerik, and M. C. Euwema, "Crossover of burnout and engagement in work teams," Work and Occupations, vol. 33, no. 4, pp. 464-489, 2006.

[79] T. Uehara, K. Sakado, M. Sakado, T. Sato, and T. Someya, "Relationship between stress coping and personality in patients with major depressive disorder," Psychotherapy and Psychosomatics, vol. 68, no. 1, pp. 26-30, 1999.

[80] M. R. Barrick and M. K. Mount, "The big five personality dimensions and job performance: a meta-analysis," Personnel Psychology, vol. 44, no. 1, pp. 1-26, 1991.

[81] J. B. Asendorpf and S. Wilpers, "Personality effects on social relationships," Journal of Personality and Social Psychology, vol. 74, no. 6, pp. 1531-1544, 1998.

[82] J. F. Finch and W. G. Graziano, "Predicting depression from temperament, personality, and patterns of social relations," Journal of Personality, vol. 69, no. 1, pp. 27-55, 2001.

[83] A. E. Poropat, "A meta-analysis of the five-factor model of personality and academic performance," Psychological Bulletin, vol. 135, no. 2, pp. 322-338, 2009.

[84] J. M. Chartrand, M. L. Rose, T. R. Elliott, C. Marmarosh, and S. Caldwell, "Peeling back the onion: personality, problem solving, and career decision-making style correlates of career indecision," Journal of Career Assessment, vol. 1, no. 1, pp. 66-82, 1993.

[85] A. Karimzade and M. A. Besharat, "An investigation of the relationship between personality dimensions and stress coping styles," Procedia-Social and Behavioral Sciences, vol. 30, pp. 797-802, 2011.

[86] J. Hogan and D. S. Ones, "Conscientiousness and integrity at work," in Handbook of Personality Psychology, R. Hogan, J. A. Johnson, and S. R. Briggs, Eds., pp. 849-870, Academic Press, 1997.

[87] S. Bergold and R. Steinmayr, "Personality and intelligence interact in the prediction of academic achievement," Journal of Intelligence, vol. 6, no. 2, p. 27, 2018.

[88] T. De Feyter, R. Caers, C. Vigna, and D. Berings, "Unraveling the impact of the Big Five personality traits on academic performance: the moderating and mediating effects of selfefficacy and academic motivation," Learning and Individual Differences, vol. 22, no. 4, pp. 439-448, 2012.

[89] G. Saucier, "Trapnell versus the lexical factor: more ado about nothing?," European Journal of Personality, vol. 8, no. 4, pp. 291-298, 1994.

[90] M. Zainah, N. A. A. Muhammad, and S. A. Nor, "Adult personality and its relationship with stress level and coping mechanism among final year medical students," Medicine \& Health, vol. 14, no. 2, pp. 154-167, 2019.

[91] C. G. DeYoung, "Openness/intellect: a dimension of personality reflecting cognitive exploration," in APA Handbook of Personality and Social Psychology: Personality Processes and Individual Differences, M. L. Cooper and R. J. Larsen, Eds., pp. 369-399, American Psychological Association, 2015. 
[92] J. B. Asendorpf and M. A. G. van Aken, "Personality-relationship transaction in adolescence: core versus surface personality characteristics," Journal of Personality, vol. 71, no. 4, pp. 629-666, 2003.

[93] M. Komarraju and S. J. Karau, "The relationship between the big five personality traits and academic motivation," Personality and Individual Differences, vol. 39, no. 3, pp. 557-567, 2005.

[94] M. R. Barrick, G. L. Stewart, and M. Piotrowski, "Personality and job performance: test of the mediating effects of motivation among sales representatives," Journal of Applied Psychology, vol. 87, no. 1, pp. 43-51, 2002.

[95] W. Strus, J. Cieciuch, and T. Rowinski, “The Polish adaptation of the IPIP-BFM-50 questionnaire for measuring five personality traits in the lexical approach," Annals of Psychology, vol. 2, pp. 347-366, 2014.

[96] L. R. Goldberg, "The development of markers for the big-five factor structure," Psychological Assessment, vol. 4, no. 1, pp. 26-42, 1992.

[97] J. F. Hair Jr., J. M. Sarstedt, L. Hopkins, and G. V. Kuppelwieser, "Partial least squares structural equation modeling (PLSSEM)," European Business Review, vol. 26, no. 2, pp. 106-121, 2014.

[98] S. Cohen, T. Kamarck, and R. Mermelstein, "A global measure of perceived stress," Journal of Health and Social Behavior, vol. 24, no. 4, pp. 385-396, 1983.

[99] B. Collis, "Pedagogical reengineering: a pedagogical approach to course enrichment and redesign with the world wide web," Educational Technology Review, vol. 8, pp. 11-15, 1997.

[100] S. Hrastinski, "A theory of online learning as online participation," Computers \& Education, vol. 52, no. 1, pp. 78-82, 2009.

[101] C. J. H. Fowler and J. T. Mayes, "Learning relationships from theory to design," Research in Learning Technology, vol. 7, no. 3, pp. 6-16, 2011.

[102] D. George and M. Mallery, SPSS for Windows Step by Step: A Simple Guide and Reference, Pearson, 10th Edition edition, 2010.

[103] C. Fornell and D. F. Larcker, "Evaluating structural equation models with unobservable variables and measurement error," Journal of Marketing Research, vol. 18, no. 1, pp. 39-50, 1981.

[104] K. J. Preacher and A. F. Hayes, "Asymptotic and resampling strategies for assessing and comparing indirect effects in multiple mediator models," Behavior Research Methods, vol. 40, no. 3, pp. 879-891, 2008.

[105] P. R. Pintrich, "The role of goal orientation in self-regulated learning," in Handbook of Self-Regulation, M. Boekaerts, P. R. Pintrich, and M. Zeidner, Eds., pp. 451-502, Academic Press, 2000.

[106] J. de la Fuente, M. Pachón-Basallo, F. H. Santos et al., "How has the COVID-19 crisis affected the academic stress of university students? The role of teachers and students," Frontiers in Psychology, vol. 12, article 626340, 2021.

[107] E. Panadero, "A review of self-regulated learning: six models and four directions for research," Frontiers in Psychology, vol. 8, p. 422, 2017.

[108] P. R. Pintrich and E. V. De Groot, "Motivational and selfregulated learning components of classroom academic performance," Journal of Educational Psychology, vol. 82, no. 1, pp. 33-40, 1990.
[109] M. Zeidner and G. Matthews, "Intelligence and personality," in Handbook of Intelligence, R. J. Sternberg, Ed., pp. 581-610, Cambridge University Press, 2000.

[110] D. Watson, Mood and Temperament, Guilford Press, 2000.

[111] T. Chamorro-Premuzic and A. Furnham, "Personality predicts academic performance: evidence from two longitudinal university samples," Journal of Research in Personality, vol. 37, no. 4, pp. 319-338, 2003.

[112] N. A. Turiano, D. K. Mroczek, J. Moynihan, and B. P. Chapman, "Big 5 personality traits and interleukin-6: evidence for "healthy Neuroticism" in a US population sample," Brain, Behavior, and Immunity, vol. 28, pp. 83-89, 2013.

[113] M. H. Cho and M. L. Heron, "Self-regulated learning: the role of motivation, emotion, and use of learning strategies in students' learning experiences in a self-paced online mathematics course," Distance Education, vol. 36, no. 1, pp. 80-99, 2015.

[114] E. Yukselturk and S. Bulut, "Predictors for student success in an online course," Journal of Educational Technology \& Society, vol. 10, no. 2, pp. 71-83, 2007.

[115] D. J. Rivers, M. Nakamura, and M. Vallance, "Online selfregulated learning and achievement in the era of change," Journal of Educational Computing Research., p. 073563312110251, 2021. 